Article

\title{
Seven-Level Active Power Filter Based on a Novel H-Bridge Power Topology Structure
}

\author{
Hanying Gao *, Pengfei Zhang, Xu Liu, Shuai Feng, Junjie Ma $®$ and Ran Li \\ School of Electrical and Electronic Engineering, Harbin University of Science and Technology, Harbin 150080, \\ China \\ * Correspondence: ghy@hrbust.edu.cn
}

Received: 8 July 2019; Accepted: 1 August 2019; Published: 3 August 2019

\begin{abstract}
This paper proposes a novel seven-level power topology, that increases the number of output levels by using fewer power switches and capacitors compared to the traditional seven-level topology. Moreover, the working mechanism of the proposed topology and its implementation method are given. Furthermore, a two-stage capacitor-voltage equalization control strategy with overall control and independent control is proposed. Finally, the proposed topology is applied to the active power filter system, and simulations and experimental research of two types of working conditions are performed. The results verify the effectiveness and feasibility of the new topology and control strategy.
\end{abstract}

Keywords: H-bridge topology; seven levels; voltage balance; active power filter

\section{Introduction}

Active power filters (APFs) are considered the best way to improve the power quality of the power supply systems because of their rapid compensation capacity and high precision [1-4]. It is difficult to apply the traditional two-level APF to high-voltage and high-power situations due to the voltage and power limitations of power switches [5]. The multilevel converter has attracted wide attention due to its low harmonic content (THD) and low electromagnetic interference (EMI) [6-9]. At present, the research on multilevel converters mainly focuses on optimizing topology and control algorithms [10-14].

There are three types of mature multilevel topologies; namely neutral point clamped (NPC), flying capacitor (FC), and cascade H-bridge (CHB) multilevel converters [15,16]. NPC and FC can significantly increase the number of power switches and DC capacitors if the number of output levels increases [17]. CHB topology can be divided into symmetric and asymmetric structures. The advantage of the symmetric topology is that the withstand voltage of the power switches can be reduced, while the disadvantage is that there are many power switches and capacitors [18]. Compared to the symmetric structure, the asymmetric structure can reduce the number of power switches to achieve the same multilevel output [19], but the key point to this topology is how to generate uniform output levels, reduce the harmonic content of the output voltage, and simplify the voltage-equalization control strategy [20-23].

For the control algorithm optimization, the main problem is the capacitor-voltage equalization; the current solution is to use the carrier phase shifted sinusoidal pulse width modulation (CPS-SPWM) to adjust the transmission power of each unit by fine-tuning the amplitude and phase of the modulated wave of each H-bridge unit [24,25]. The disadvantage of this method is that when the modulated wave of each unit is adjusted, the lower harmonics in the phase voltage cannot be eliminated, which results in the distortion of the output voltage waveform [26]. In contrast to the power distribution technology based on the CPS-SPWM, in the literature $[27,28]$, the modulation technology of the carrier disposition 
and carrier rotation is proposed to realize multilevel output, and the power balancing distribution of each element is also realized. However, the power-balance control strategy is not given. In addition, methods based on step-wave modulation technology, multi-frequency power allocation, etc. have been proposed, but there are some limitations in terms of harmonic performance, implementation difficulty, and power balance distribution, etc. [29,30].

This paper proposes a novel seven-level power topology. Compared to other traditional seven-level topologies, it can reduce the number of power switches and capacitors, increase the number of output levels, and reduce the harmonic content of the output voltage and the complexity of the system. This paper deeply analyzes the working mechanism of the novel power topology and gives the engineering realization of the proposed topology. At the same time, an equalization control strategy with overall control and independent control of two-stage capacitor voltage is proposed to solve the problem of the capacitor-voltage imbalance in applications. Finally, the novel topology is applied to the three-phase APF system, and the harmonic suppression control strategy and cell capacitor-voltage regulation are proposed. The simulation and experimental work are carried out under different working modes, and the results verify the correctness and feasibility of the proposed novel topology and control strategy.

\section{Analysis of the Novel Seven-Level Topology}

\subsection{The Structure and Working Mechanism of the Novel Seven-Level H-Bridge Topology}

Figure 1 shows the main circuit of a novel seven-level APF. The three-phase units have the same structure; A phase contains six power switches $S_{a 1}-S_{a 6}$ and two capacitors $C_{a 1}$ and $C_{a 2}$ which are called the seven-level H-bridge topology. As can be seen from the dotted box in Figure 1, when $S_{a 1}, S_{a 2}$ (or $S_{a 3}, S_{a 4}$ ) are simultaneously turned on, $C_{a 1}$ (or $C_{a 2}$ ) is short-circuited, so $S_{a 1}, S_{a 2}$ (or $S_{a 3}, S_{a 4}$ ) must work in a complementary state. In addition, when $S_{a 5}$ and $S_{a 6}$ are simultaneously turned on, $C_{a 1}$ and $C_{a 2}$ are also short-circuited, so $S_{a 5}$ and $S_{a 6}$ also work in a complementary state. As can be seen from Table 1 , the novel topology has seven working states. Among them, $S_{a 5}$ and $S_{a 6}$ work at low frequency, which is consistent with the modulation wave frequency. The switching frequency of $S_{a 1}$ and $S_{a 2}$ is half of $S_{a 3}$ and $S_{a 4} . V_{1}$ and $V_{2}$ are the voltages of $C_{a 1}$ and $C_{a 2}$, respectively, $V_{1}=2 V_{2}$. Inductors $L_{A}, L_{B}$, and $L_{C}$ connect the converter to the power grid, balance the voltage difference between the grid and the converter output, and perform reactive compensation or harmonic suppression.

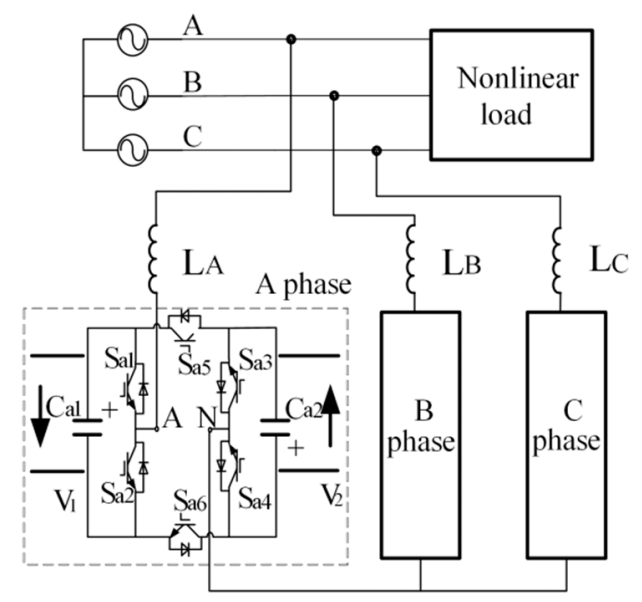

Figure 1. Seven-level active power filter (APF) main circuit. 
Table 1. Switching states of the seven-level topology.

\begin{tabular}{cccc}
\hline \multicolumn{3}{c}{ Switch Status } & Output Level \\
\cline { 1 - 3 } $\boldsymbol{S}_{a 1}, \boldsymbol{S}_{\boldsymbol{a} \mathbf{2}}$ & $\boldsymbol{S}_{a \mathbf{a}}, \boldsymbol{S}_{a \mathbf{a}}$ & $\boldsymbol{S}_{a 5}, \boldsymbol{S}_{\boldsymbol{a} \mathbf{}}$ & \\
\hline 1,0 & 1,0 & 0,1 & $+\left(V_{1}+V_{2}\right)$ \\
1,0 & 0,1 & 0,1 & $+V_{1}$ \\
0,1 & 1,0 & 0,1 & $+V_{2}$ \\
1,0 or 0,1 & 1,0 or 0,1 & 1,0 or 0,1 & 0 \\
1,0 & 0,1 & 1,0 & $-V_{2}$ \\
0,1 & 1,0 & 1,0 & $-V_{1}$ \\
0,1 & 0,1 & 1,0 & $-\left(V_{1}+V_{2}\right)$ \\
\hline
\end{tabular}

\subsection{Comparison with Other Seven-Level Structures}

Table 2 shows the comparison of the novel topology with the traditional diode-clamped and cascaded seven-level converters, in which the number of power switches per phase is 6,12 , and 12 , and the number of capacitors is 2,6 , and 3, respectively. It can be seen that the structure of the novel topology is simple, and reduces the system volume. At the same time, considering the withstand voltage limit, the novel topology is suitable for medium-voltage and low-voltage situations.

Table 2. Seven-level topology comparison.

\begin{tabular}{|c|c|c|c|}
\hline $\begin{array}{ll}\text { Category } & \text { Structure } \\
\end{array}$ & Diode Clamp & Cascading H-Bridge & New Topology \\
\hline \multicolumn{4}{|l|}{ Topology } \\
\hline Number of single-phase power switches & 12 & 12 & 6 \\
\hline Number of single-phase capacitors & 6 & 3 & 2 \\
\hline
\end{tabular}

\section{APF Control Method Based on Novel Topology Structure}

\subsection{Overall Control Strategy of the System}

Figure 2 shows the diagram of the overall control structure of the novel APF system, including the harmonic current control unit and the capacitor-voltage stage control unit. In the harmonic current control unit, the output $u_{f}$ could be obtained based on the $i p-i q$ current detection method and quasi-proportional resonance (PR), repetitive control strategy. Considering that the imbalance of the capacitor voltage is caused by switch loss and drive pulse delay, the inverter output voltage is distorted, so the capacitor voltage must be regulated. Figure 2 shows the capacitor-voltage stage control unit, which uses a two-stage capacitor-voltage control strategy with overall control and independent control to obtain two-stage outputs $u_{1 f}$ and $u_{2 f}$. Finally, the harmonic current control and the capacitor-voltage stage control are combined to obtain $u_{a}, u_{b}$, and $u_{c}$. The carrier disposition is modulated to generate a pulse-width-modulated (PWM) signal, and the power amplifier drives the power switches to achieve harmonic suppression and capacitor-voltage regulation. The following cases, without loss of generality, are illustrated with the A phase as an example. 


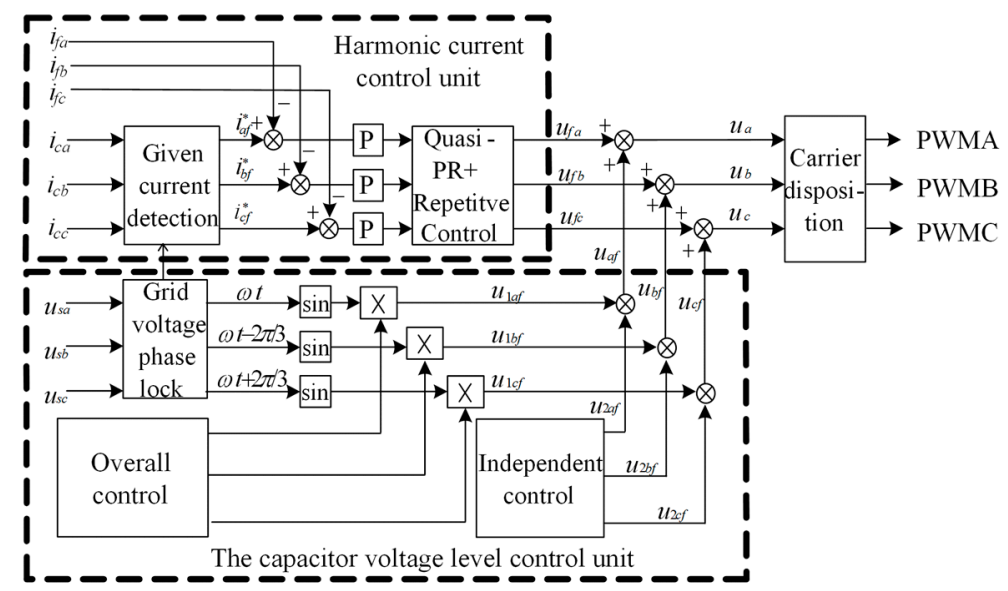

Figure 2. The overall control structure of the new APF system.

\subsection{First-Stage Control Strategy of the Capacitor Voltage}

The first stage is the overall control of capacitor $C_{a 1}$ and $C_{a 2}$, as shown in Figure 3a. Proportional integral regulator (PI) adjustment is performed for the sum of the given capacitor-voltage $\left(V_{\text {ref } 1}+V_{\text {ref } 2}\right)$ and the sum of the actual capacitor-voltage $\left(V_{a 1}+V_{a 2}\right)$. Its output is multiplied by the unit sine of the A-phase grid voltage to obtain the modulated wave $\mathrm{u}_{1 \mathrm{af}}$ to realize the overall voltage control of the A-phase units $C_{a 1}$ and $C_{a 2}$, and obtain $V_{r e f 1}+V_{r e f 2}=V_{a 1}+V_{a 2}$.

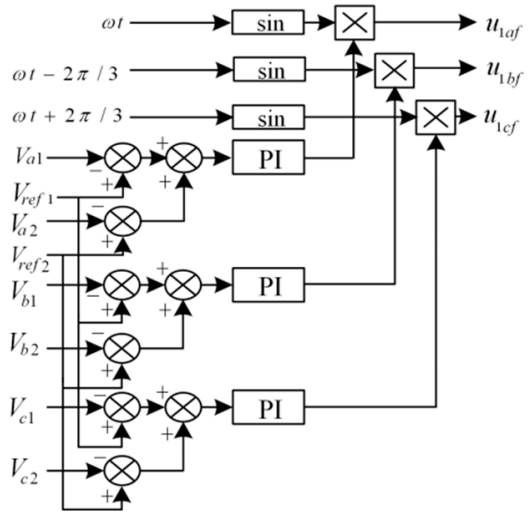

(a)

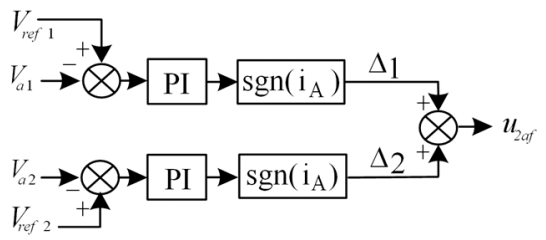

(b)

Figure 3. Control strategy of the capacitor voltage: (a) Overall control, (b) Independent control.

\subsection{Second-Stage Control Strategy of the Capacitor Voltage}

The second stage is the independent control of capacitors $C_{a 1}$ and $C_{a 2}$, as shown in Figure $3 b$, which consists of the determination of charge and discharge status and the control strategy of charge and discharge; $\operatorname{sgn}\left(i_{A}\right)$ is the symbol function of $i_{A}$.

\subsubsection{Determination of Charge and Discharge Status}

Figure 4 shows the operating state of the unit circuit when $C_{a 1}$ and $C_{a 2}$ in the A-phase are charged and discharged, where $i_{A}$ is the output current. Table 3 gives the charge and discharge status of $C_{a 1}$ and $C_{a 2}$. First, the charge and discharge status of $C_{a 1}$ and $C_{a 2}$ are judged by the unit output status and the direction of $i_{A}$. When the status is 1 or 7 (Table 3), if the charge and discharge of $C_{a 1}$ and $C_{a 2}$ are carried out, the output of the unit will change. At the same time, considering that $C_{a 1}$ and $C_{a 2}$ are suspended at state 4 , the charge and discharge are not adjusted under these three conditions. 

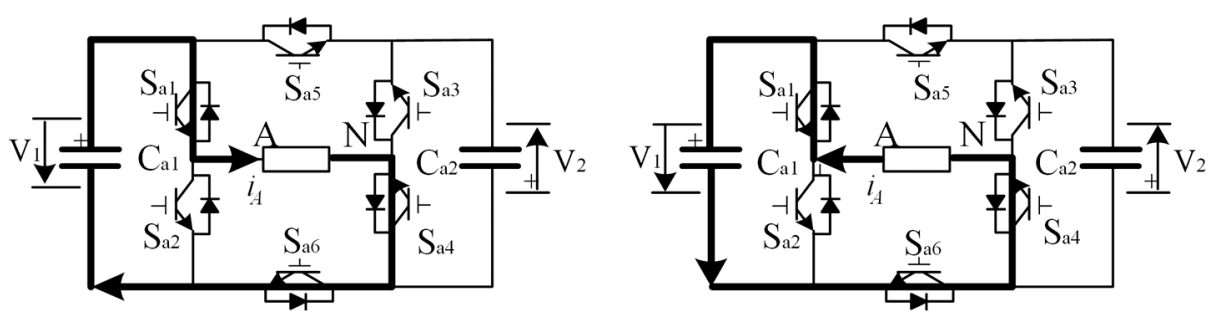

(a)
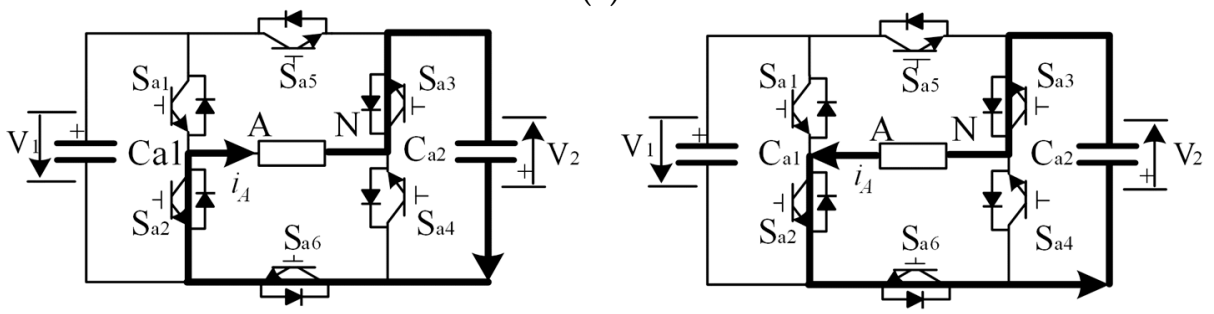

(b)
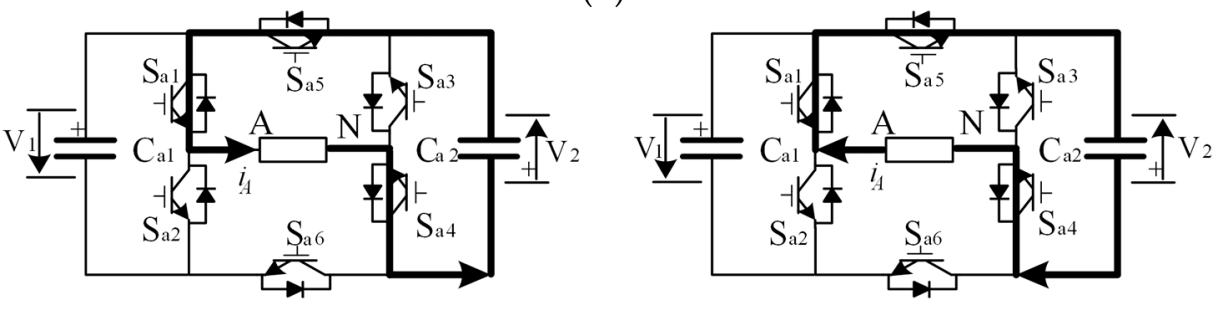

(c)
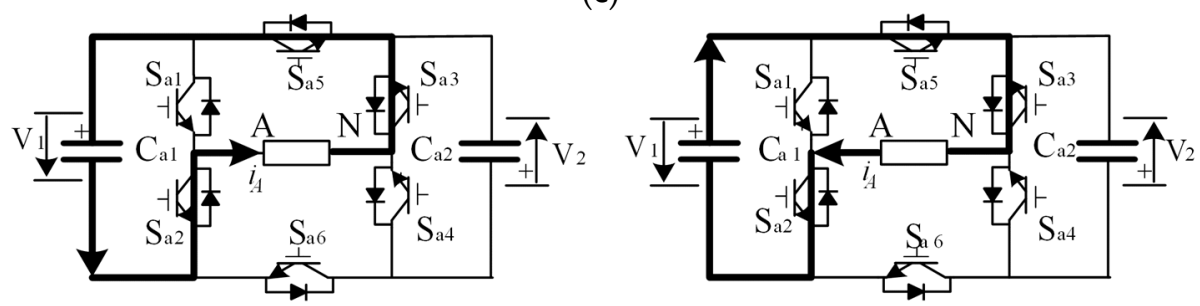

(d)

Figure 4. Circuit state during $C_{a 1}, C_{a 2}$ charge and discharge: (a) Level 6; $i_{A}>0, i_{A}<0$; (b) Level 5; $i_{A}>0, i_{A}<0 ;$ (c) Level 3; $i_{A}>0, i_{A}<0 ;$ (d) Level 2; $i_{A}>0, i_{A}<0$.

Table 3. State determination of $C_{a 1}, C_{a 2}$ charge and discharge.

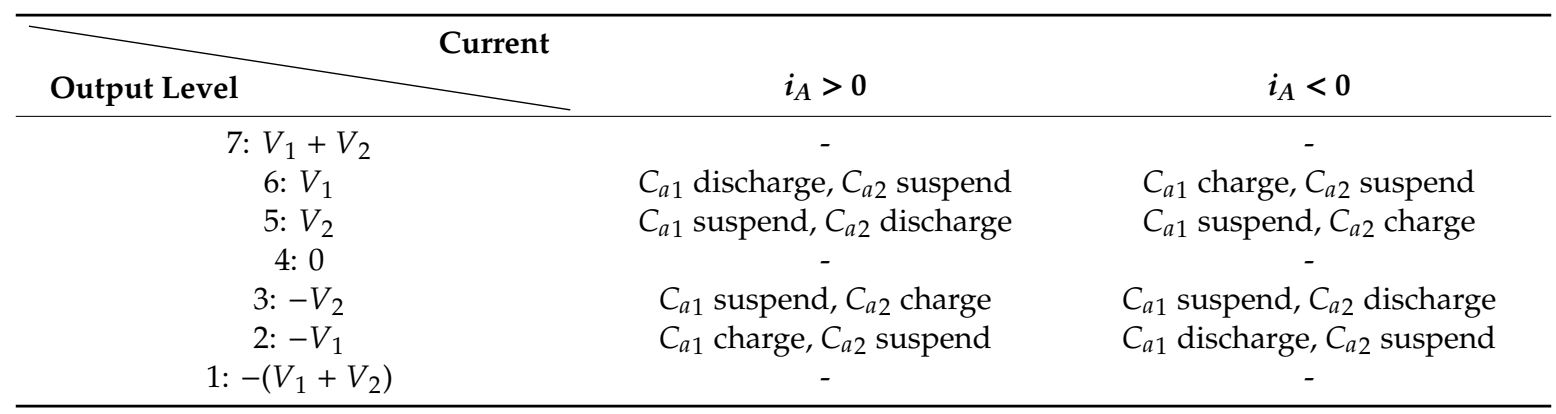

\subsubsection{Control Strategy of Charge and Discharge}

Figure $3 \mathrm{~b}$ shows the charge and discharge control of $C_{a 1}$ and $C_{a 2}$. The actual voltage $V_{a 1}, V_{a 2}$ and the reference voltage $V_{\text {ref } 1}, V_{\text {ref } 2}$ are, respectively subjected to PI adjustment to obtain $\Delta 1, \Delta 2$, and $U_{2 a f}$ could be obtained after synthesis. Figure 5 shows a schematic diagram of the seven-level phase capacitor-voltage adjustment. The six-layer carriers output seven level states, which are defined as levels 1-7 from low to high. According to the carrier-disposition modulation principle, when the modulated wave is located in area 1 or 2, it outputs six levels (corresponding to $V_{1}$ in Table 3 ). If the 


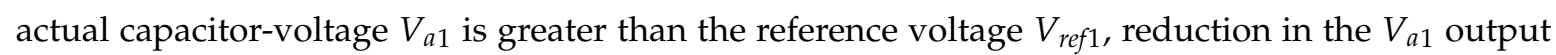
could be achieved by increasing the discharging time of $C_{a 1}$ or shortening the charging time of $C_{a 1}$. When $C_{a 1}$ is in a discharged state, if the modulated wave is compared with carrier 6 at that moment, the output is level 6 or level 7, if the amplitude of the modulated wave is decreased, and the output time of level 6 could be increased accordingly, that is, the discharge time of $C_{a 1}$ is increased. Similarly, when $C_{a 1}$ is in the charge state, the charging time of $C_{a 1}$ could be reduced by changing the amplitude of the modulated wave. The voltage adjustment of $C_{a 2}$ is the same as that of $C_{a 1}$. It can be seen that the capacitor-voltage stabilization can be achieved by changing the amplitude of the modulated wave.

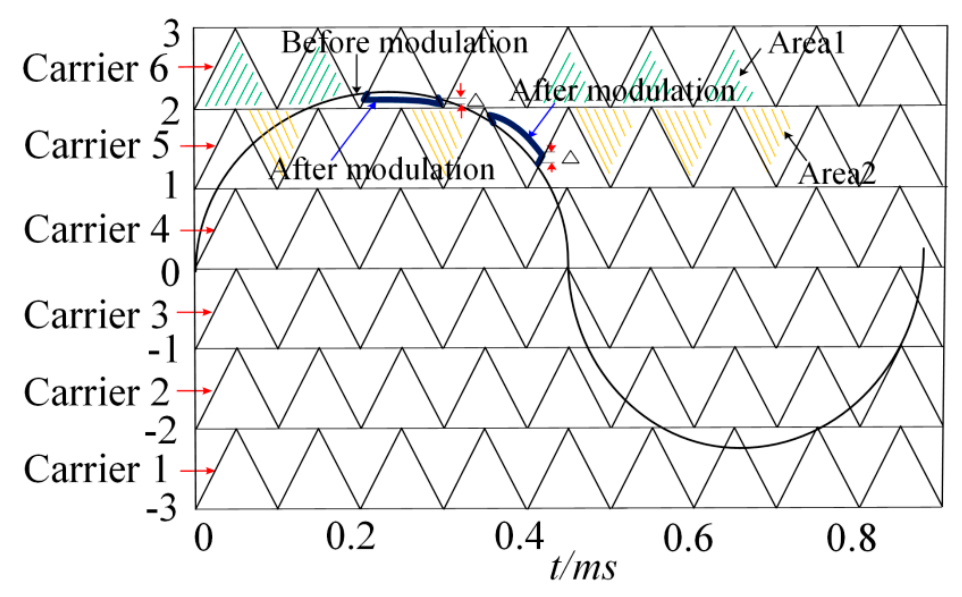

Figure 5. Unit capacitor-voltage regulator schematic.

\subsection{Parameter Calculation of Passive Elements}

The larger the connected inductance value of APF is, the smaller the current ripple, but the smaller the rate of change of the compensation currens, and the weaker the current tracking ability. Secondly, the compensation current should be able to track the maximum rate of change of the command current. The smaller the inductance value is, the higher the rate of change of the current, and the faster the dynamic response speed of APF. However, the more drastic the current change is, the larger the ripple of the current. The DC side capacitor provides a stable DC power supply for the APF. The larger the capacitance, the more stable the DC side voltage. As the capacitor capacity increases, the volume and cost of the capacitor also increases.

\subsubsection{Parameter Calculation of Connected Inductor}

a. Inductance parameter selection based on ripple constraint condition

The equivalent circuit of the APF device is shown in Figure 6, we can get:

$$
u-e=L \frac{d i_{c}}{d t}
$$

where $u$ is the AC side voltage of the inverter, $e$ is the grid side voltage, $L$ is the connection inductance, and $i_{c}$ is the compensation current. 


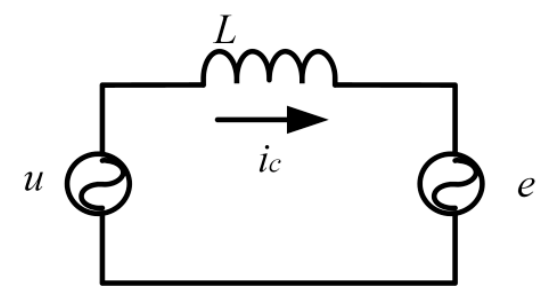

Figure 6. The equivalent circuit of the APF device.

In the process of the harmonic current compensation of $\mathrm{APF}$, high-frequency harmonic components exist in the output of the AC side, which generates a ripple current under the action of inductance, and the ripple is the largest at the peak of the output current. Figure 7 shows, in a multilevel inverter, $N U_{d c}$ and $(N-1) U_{d c}$ levels are included at the peak output current of thr AC side. It is assumed that the high-level duration of $N U_{d c}$ is $t_{1}$ and the low-level duration of $(N-1) U_{d c}$ is $t_{2}$ in a switching period Ts, when the output current is at the peak, applying $u=N U_{d c}, d i_{c} / d_{t}=\Delta i_{c} / T_{c}$ into Equation (1), we can get:

$$
\left\{\begin{array}{l}
N U_{d c}-e=L \frac{\Delta i_{1}}{t_{1}} \\
e-(N-1) U_{d c}=L \frac{\Delta i_{2}}{t_{2}}
\end{array}\right.
$$

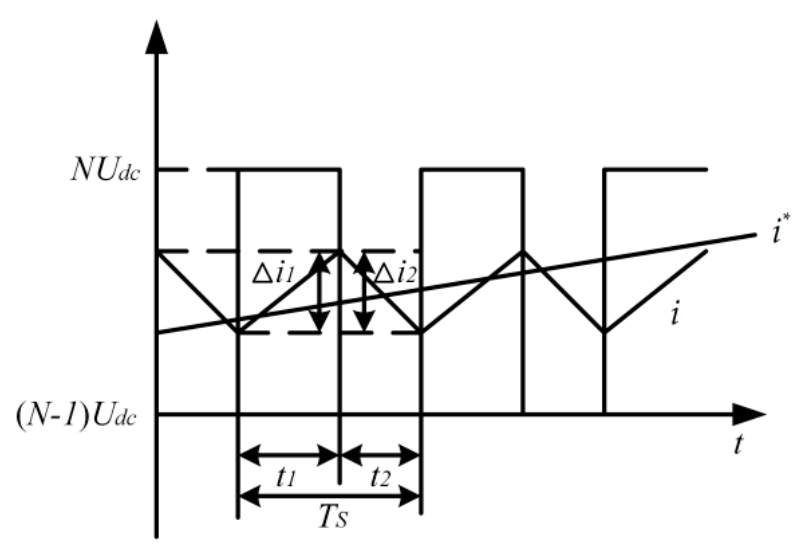

Figure 7. Current ripple at current peak.

When the output current is at the peak, it satisfies $\Delta i_{1}=\Delta i_{2}, t_{1}+t_{2}=T_{s}$. Applying them into Equation (1):

$$
\begin{gathered}
t_{1}=\frac{e-(N-1) U_{d c}}{U_{d c}} T_{s} \\
\Delta i_{1}=\frac{\left(N U_{d c}-e\right)\left[e-(N-1) U_{d c}\right]}{L U_{d c}} T_{s} \\
L=\frac{\left(N U_{d c}-e\right)\left[e-(N-1) U_{d c}\right]}{\Delta i_{1} U_{d c}} T_{s}
\end{gathered}
$$

It can be seen from Equation (4) that increasing the connected inductance $L$ can reduce the ripple current $\Delta i_{1}$. In practical engineering, the ripple current usually takes $5 \%$ of the compensation current peak value. Thus, the lower limit of connection inductance could be obtained:

$$
L \geq \frac{\left(N U_{d c}-e\right)\left[e-(N-1) U_{d c}\right]}{\Delta i_{\max } U_{d c}} T_{s}
$$

In the Equation (6), $f_{s}=20 \mathrm{kHz}, N=3, U_{d c}=130 \mathrm{~V}, e=311 \mathrm{~V}$, we can get:

$$
L \geq 1.55 \mathrm{mH}
$$


b. Inductance parameter selection based on the tracking ability of the compensation current at zero crossing

During one cycle of the command current, it changes the fastest at zero-crossing point $(w t=0)$, and the upper limit of the connected inductance could be determined according to the rate of change of the command current at zero. The current tracking waveform is shown in Figure 8. $\Delta i_{1}$ and $\Delta i_{2}$ are the current increments across the connected inductor during $t_{1}$ and $t_{2}$, and $T_{S}$ is a PWM switching cycle.

$$
\begin{gathered}
U_{d c}-e=L \frac{\Delta i_{1}}{t_{1}} \\
e-0=L \frac{\Delta i_{2}}{t_{2}}
\end{gathered}
$$

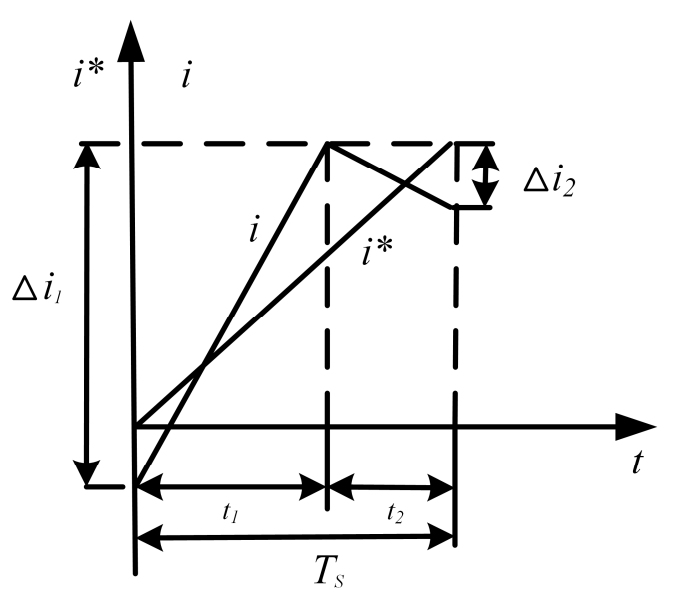

Figure 8. Current ripple at the current zero-crossing point.

It can be seen from Equations (8) and (9) that the current has a maximum rate of change at the current zero-crossing point. When $t_{1}=T_{S}, t_{2}=0, \Delta i_{2}=0, \Delta i_{1}=\Delta i, e=0$, we can get:

$$
\begin{gathered}
\left.\frac{d\left(I_{m} \sin \omega t\right)}{d t}\right|_{t=0}=\left.I_{m} \omega \cos \omega t\right|_{t=0}=\omega I_{m} \\
\frac{U_{d c}}{L_{\max }}=\omega I_{m}
\end{gathered}
$$

where $I_{m}$ is the current peak, we can get:

$$
L_{\max } \leq \frac{U_{d c}}{\omega I_{m}}
$$

where $U_{d c}=130 \mathrm{~V}, I_{m}=28.28 \mathrm{~A}, f=50 \mathrm{~Hz}, w=2 \pi f$, we can get:

$$
L \leq 14.6 \mathrm{mH}
$$

According to Equations (7) and (13), the value of the connected inductor $L_{A}, L_{B}$, and $L_{C}$ could be selected as $3 \mathrm{mH}$.

\subsubsection{Parameter Calculation of Capacitor}

The main considerations for the DC-side capacitors are: switching frequency $f_{s}$, average value of DC bus voltage $U_{\text {dcavg }}$, DC bus voltage ripple rate $\gamma_{v}$, and current peak $I_{m}$. 
The DC bus voltage ripple rate $\gamma_{v}$ could be expressed as:

$$
\gamma_{v}=\frac{U_{d c \max }-U_{d c a v g}}{U_{d c a v g}}=\frac{U_{d c a v g}-U_{d c \min }}{U_{d c a v g}}
$$

where $U_{d c m a x}$ and $U_{d c m i n}$ are the maximum value and the minimum value of the DC bus voltage, respectively.

From Equation (14), we can get:

$$
\begin{aligned}
& U_{d c \max }=\left(1+\gamma_{v}\right) U_{d c a v g} \\
& U_{d c \min }=\left(1-\gamma_{v}\right) U_{d c a v g}
\end{aligned}
$$

Since $Q=i t, Q=C U$, there is:

$$
\Delta U_{d c \max }=U_{d c \max }-U_{d c a v g}=\gamma_{v} U_{d c a v g}=\frac{\Delta Q}{C}=\frac{1}{C} T_{s} I_{m}
$$

According to Equation (17), it could be inferred that the DC side capacitor $C$ is:

$$
C=\frac{1}{\gamma_{v} U_{\text {dcavg }}} T_{s} I_{m}=\frac{1}{\gamma_{v} U_{\text {dcavg }} f_{s}} I_{m}
$$

where $\gamma_{v}$ is $0.9 \%, f_{s}$ is $20 \mathrm{kHz}, U_{\text {dcavg }}$ is $390 \mathrm{~V}, I_{m}$ is $28.28 \mathrm{~A}$, then $\mathrm{C}=403 \mathrm{uF}$, the value of the capacitor $C_{a 1}$ and $C_{a 2}$ could be selected as $1000 \mathrm{uF}$.

\section{System Simulation and Result Analysis}

In order to verify the correctness and feasibility of the proposed topology, voltage-balance control strategy, and its application in the APF system, the following simulation is conducted. The parameters of the simulation are as follows: the voltage of the capacitor $C_{a 1} U_{d 1}$ is $260 \mathrm{~V}$, the voltage of the capacitor $C_{a 2} U_{d 2}$ is $130 \mathrm{~V}$, the grid frequency $f$ is $50 \mathrm{~Hz}$, he switching frequency $f_{s}$ is $20 \mathrm{kHz}$, and the inductance $L$ is $3 \mathrm{mH}$.

\subsection{Under the Conditions of Balanced Grid and Load}

The grid voltages $U_{A}, U_{B}$, and $U_{C}$, are all $220 \mathrm{~V}$, and the rectifier bridge is followed by the resistance of $40 \Omega$. Figures 9 and 10 show the gird current in the A-phase and its THD before and after compensation, where the THD decreases from $24.03 \%$ to $1.10 \%$. As shown in Figure 10a, before $0.3 \mathrm{~s}$, the system load is a three-phase rectifier bridge with a resistance of $40 \Omega$, at $0.3 \mathrm{~s}$, a resistance of $40 \Omega$ is connected in parallel, and after $0.35 \mathrm{~s}$, the load is changed to $40 \Omega$. It can be seen that in the case of a sudden change of load, the grid current fluctuates slightly, and tracks the reference input quickly, the voltage fluctuation is small, and there is no mutation substantially. Figure 11 shows the voltage of each capacitor, the fluctuation does not exceed $1 \mathrm{~V}$, and it also shows the unit output, which is seven levels. 


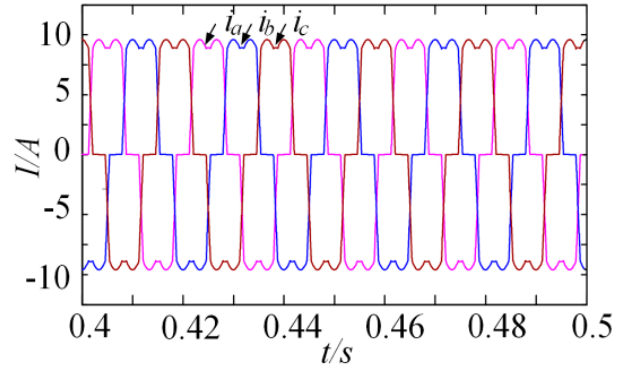

(a)

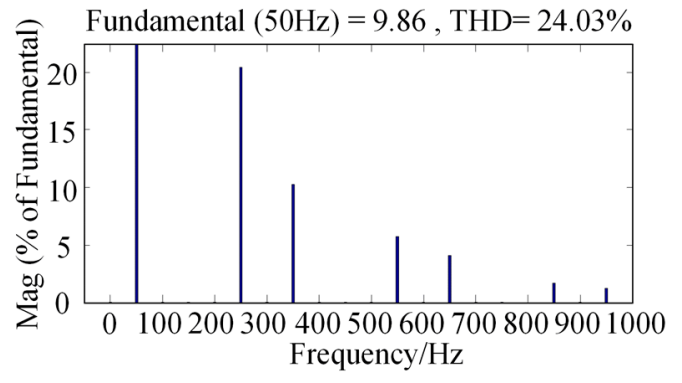

(b)

Figure 9. Before compensation: (a) Grid current; (b) Current Total Harmonic Distortion (THD).

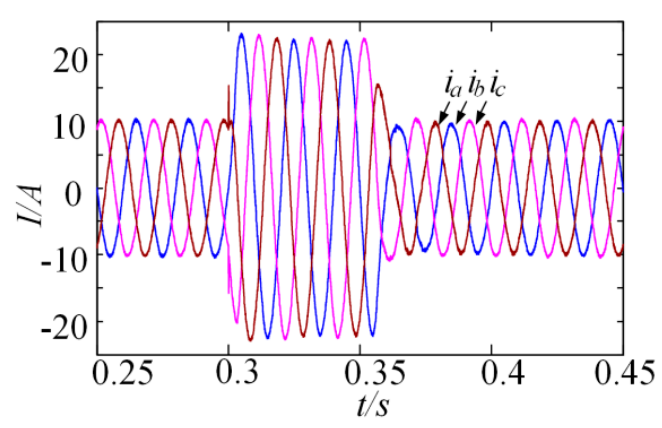

(a)

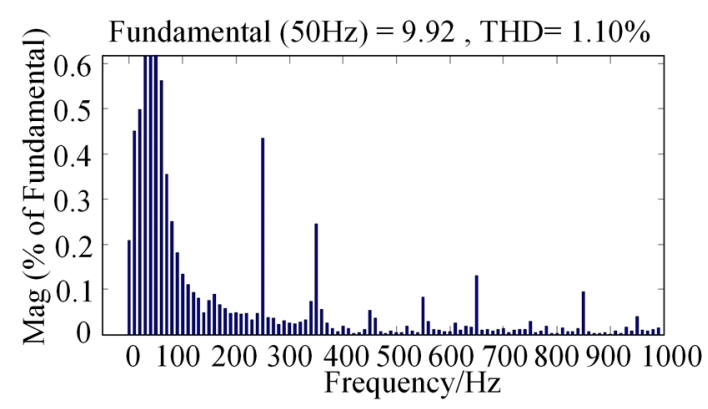

(b)

Figure 10. After compensation: (a) Grid current; (b) Current THD.

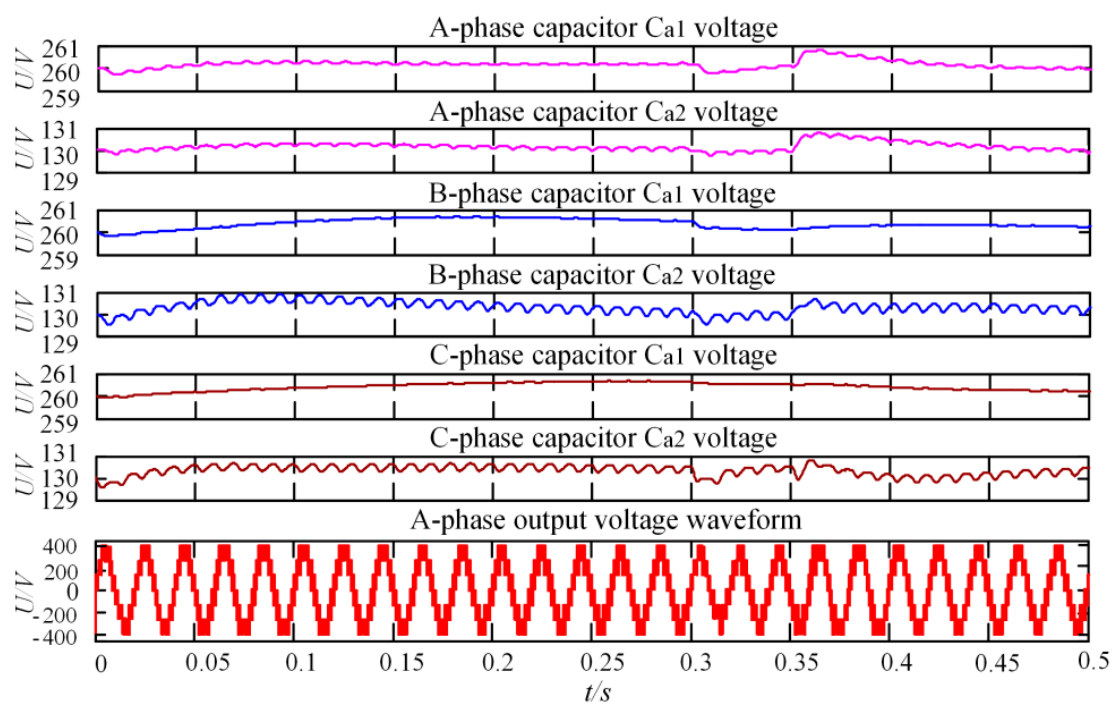

Figure 11. Each capacitor-voltage and the A-phase output voltage waveform.

\subsection{Under the Conditions of Unbalanced Grid and Load}

The grid phase voltages $U_{A}, U_{B}$, and $U_{C}$, are $220 \mathrm{~V}, 180 \mathrm{~V}$, and $180 \mathrm{~V}$, respectively. A single-phase rectifier load with a resistance of $10 \Omega$ is connected between the A-phase and the B-phase, and the three-phase rectifier bridge is followed by a resistance of $40 \Omega$. Figures 12 and 13 show the grid current and its current THD before and after compensation. It can be seen that the THD decreases from $20.98 \%$ to $1.89 \%$, and the compensation effect is obvious. As shown in Figure 13a, before $0.3 \mathrm{~s}$, the system load is a three-phase rectifier bridge with a resistance of $40 \Omega$, at $0.3 \mathrm{~s}$, a resistance of $40 \Omega$ is connected in parallel, and after $0.35 \mathrm{~s}$, the load is changed to $40 \Omega$. It can be seen that in the case of a sudden change 
in system load, the grid current fluctuates slightly, and track the reference input quickly, the voltage fluctuation is small, and there is no substantial mutation. Figure 14 shows the voltage waveforms of each capacitor, which enter the steady-state at $0.05 \mathrm{~s}$, and the fluctuation does not exceed $1 \mathrm{~V}$, and it also shows the unit output of the novel power topology, which is seven levels.

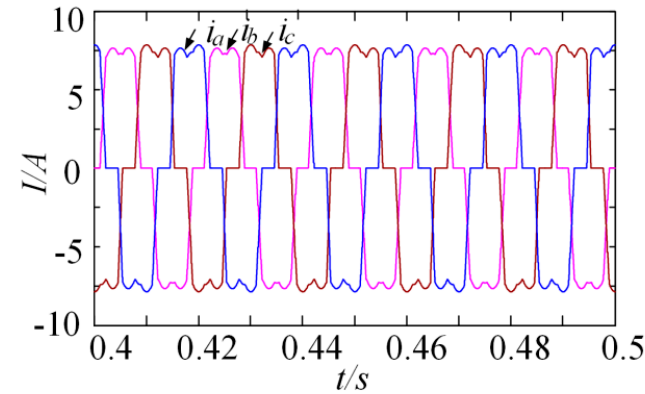

(a)

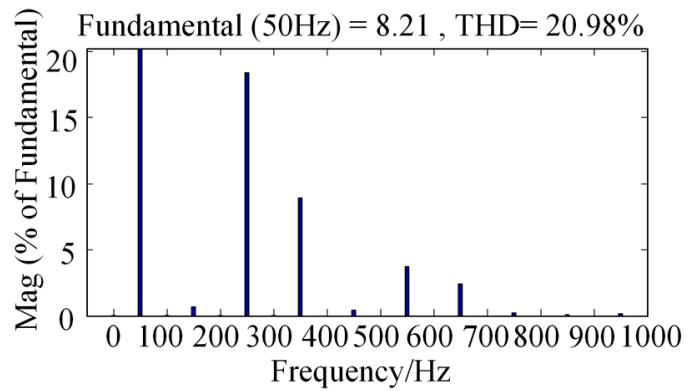

(b)

Figure 12. Before compensation: (a) Grid current; (b) Current THD.

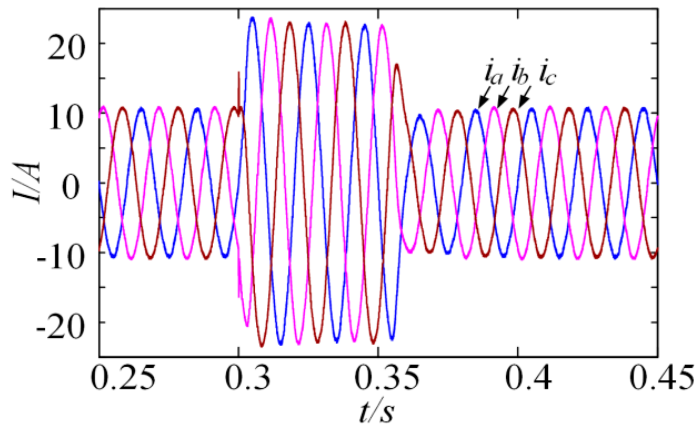

(a)

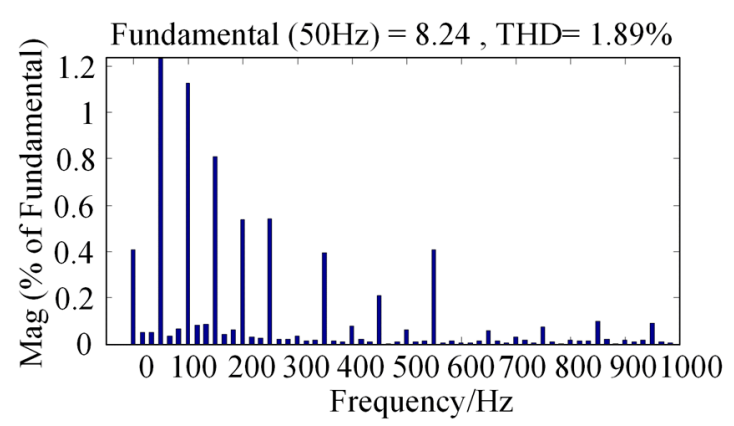

(b)

Figure 13. After compensation: (a) Grid current; (b) Current THD.

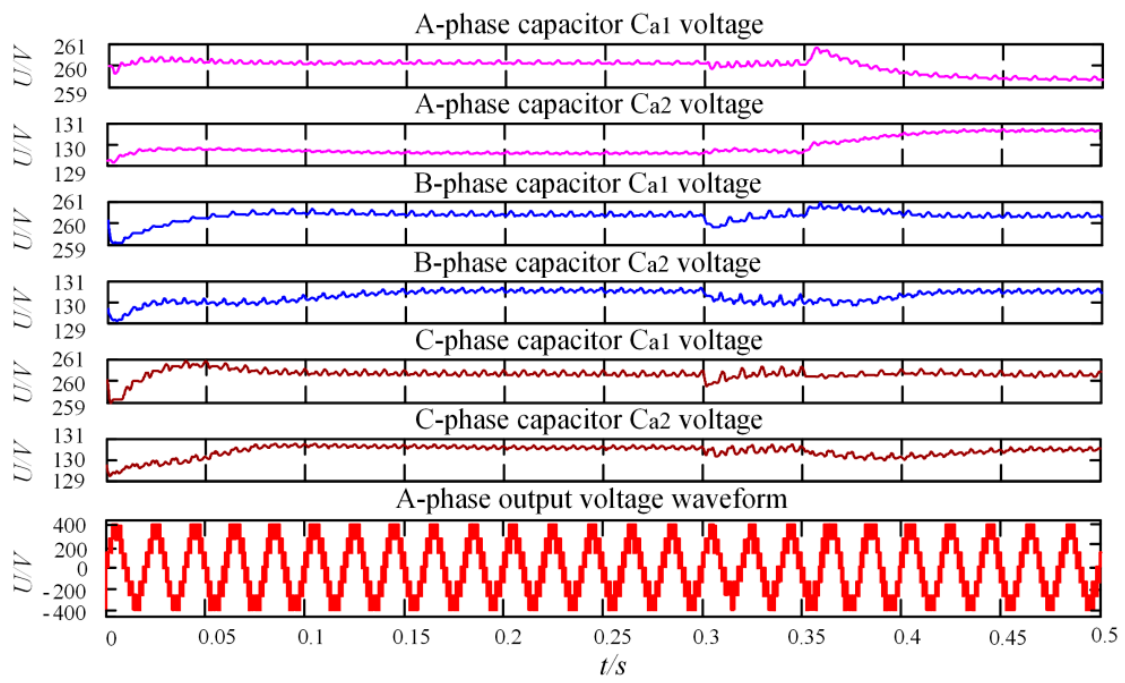

Figure 14. Each capacitor-voltage and the A-phase output voltage waveform. 


\section{Experiment and Result Analysis}

In order to verify the correctness and feasibility of the proposed topology, the voltage-balance control strategy, and its application in the APF system, the following experiment is conducted. Table 4 shows the parameters of the experiment, and the experiment system platform is shown in Figure 15.

Table 4. Main parameters of the system.

\begin{tabular}{cc}
\hline System Parameters & Values \\
\hline The voltage of capacitor $C_{a 1}$ & $260 \mathrm{~V}$ \\
The voltage of capacitor $C_{a 2}$ & $130 \mathrm{~V}$ \\
The capacitor $C_{a 1}$ & $1000 \mathrm{uF}$ \\
The capacitor $C_{a 2}$ & $1000 \mathrm{uF}$ \\
The switching frequency $f_{s}$ & $20 \mathrm{kHz}$ \\
The grid frequency $f$ & $50 \mathrm{~Hz}$ \\
The inductor $L_{A}, L_{B}, L_{C}$ & $3 \mathrm{mH}$ \\
The balanced grid phase voltages $U_{A}, U_{B}, U_{C}$ & $220 \mathrm{~V}$ \\
The balanced resistance load $R$ & $40 \Omega$ \\
The unbalanced grid phase voltages $U_{A}, U_{B}, U_{C}$ & $220 \mathrm{~V}, 180 \mathrm{~V}, 180 \mathrm{~V}$ \\
A single-phase rectifier load $R_{A B}$ & $10 \Omega$ \\
\hline
\end{tabular}

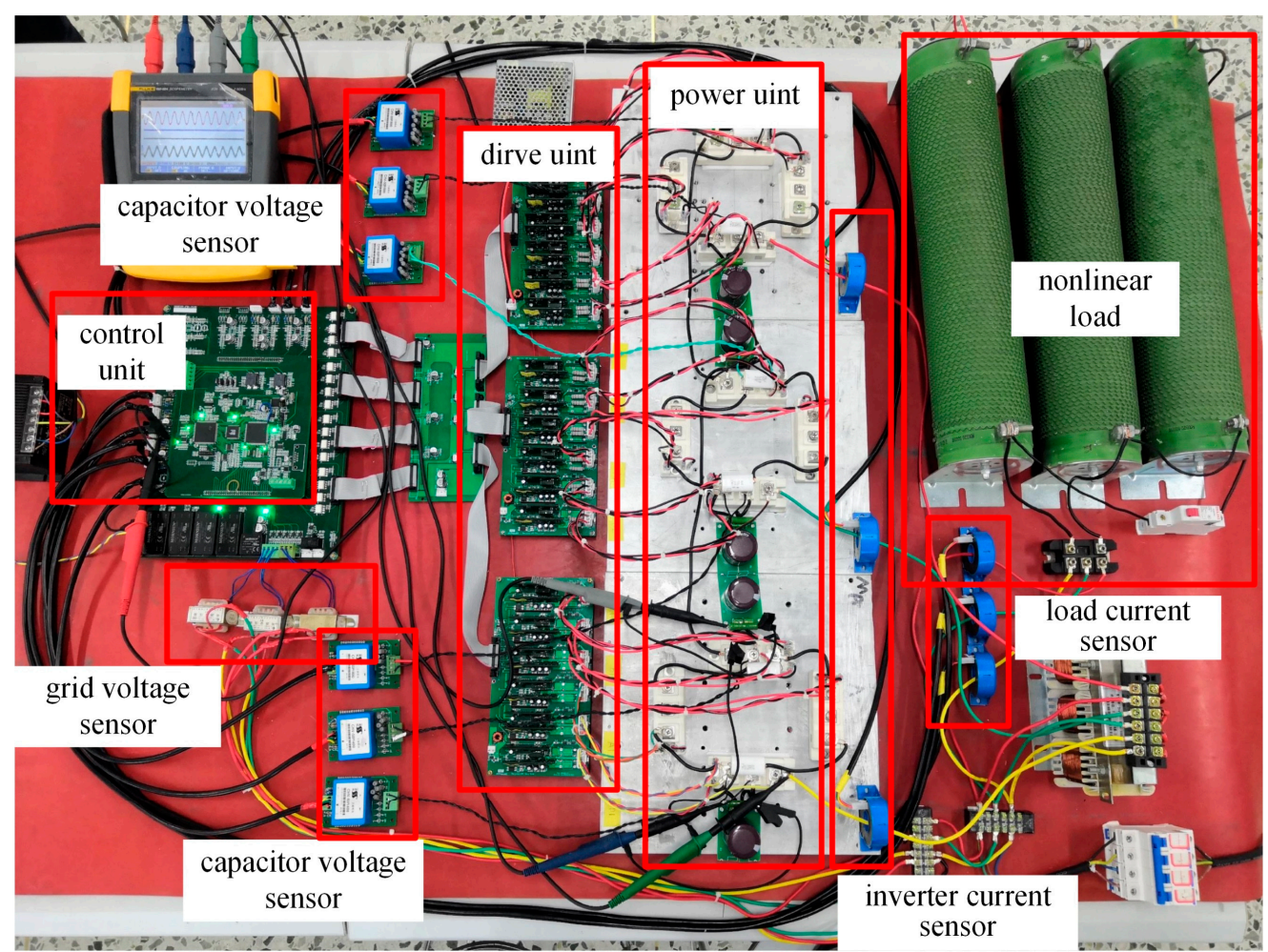

Figure 15. Experiment system platform.

\subsection{Under the Conditions of Balanced Grid and Load}

The grid phase voltages $U_{A}, U_{B}$, and $U_{C}$, are all $220 \mathrm{~V}$, and the rectifier bridge is followed by the resistance of $40 \Omega$. Figures 16 and 17 show the grid current waveforms of the A-phase and its THD before and after compensation, where the phase current THD is reduced from $29.49 \%$ to $2.79 \%$, and the compensation effect is obvious. At the same time, the dynamic compensation performance of the system was studied. The rectifier was connected with a $40 \Omega$ resistance load, then a $40 \Omega$ load resistance was connected in parallel, and finally removed. It can be seen from Figure 17a that $U_{a 1}$ and $U_{a 2}$ are stable at a reference value, and the system has good dynamic compensation performance if the 
power grid and load are all balanced, and it also shows the unit output of the novel power topology, which is seven levels.

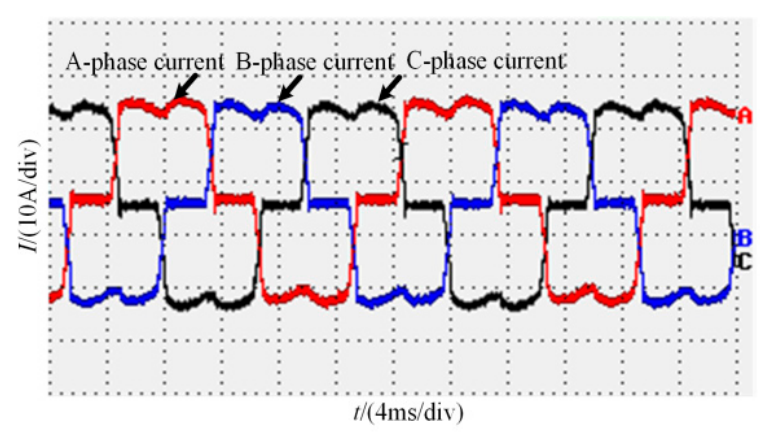

(a)

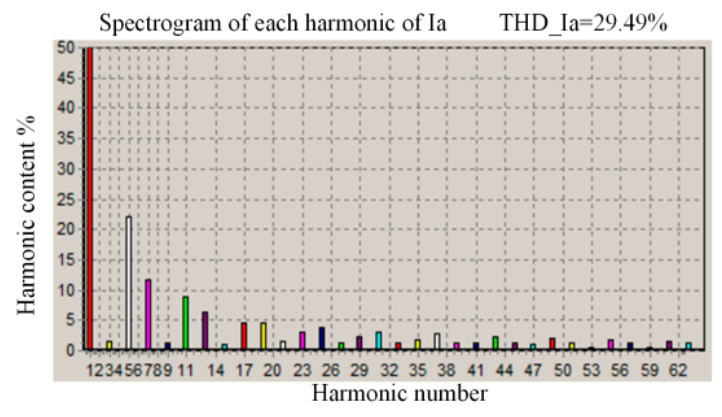

(b)

Figure 16. Before compensation: (a) Grid current; (b) Current THD.

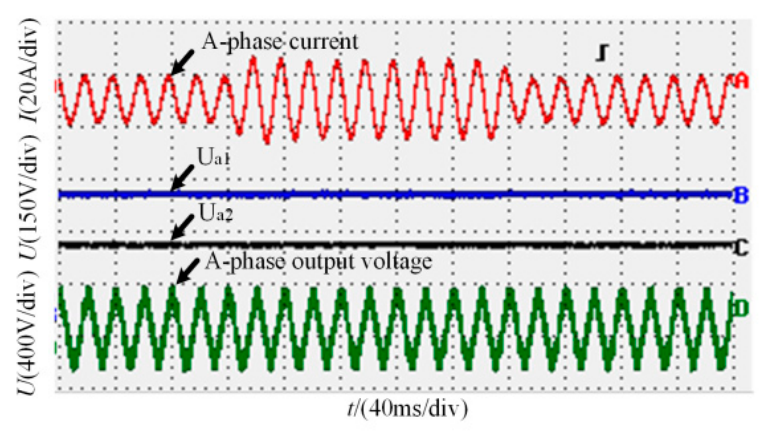

(a)

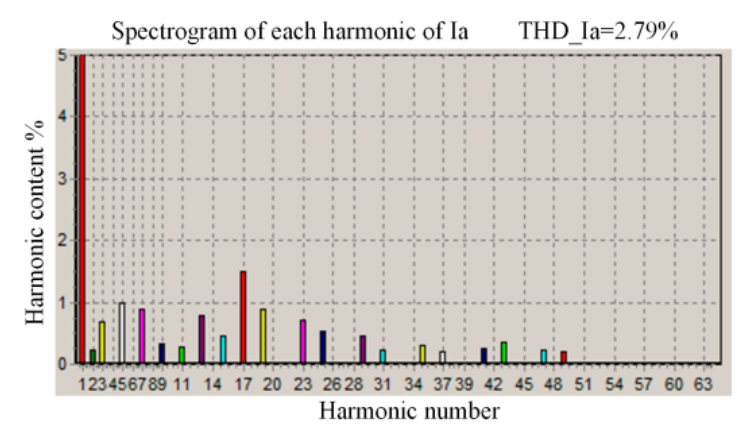

(b)

Figure 17. After compensation: (a) Grid current, two capacitor voltages, and the output voltage of the A-phase; (b) Current THD.

\subsection{Under the Conditions of Unbalanced Grid and Load}

The grid phase voltages $U_{A}, U_{B}$, and $U_{C}$ are $220 \mathrm{~V}, 180 \mathrm{~V}$, and $180 \mathrm{~V}$, respectively. A single-phase rectifier load with a resistance of $10 \Omega$ is connected between A phase and B phase, and the three-phase rectifier bridge is followed by a resistance of $40 \Omega$. Figures 18 and 19 show the grid current and its current THD before and after compensation. It can be seen that the THD decreases from $30.24 \%$ to $3.13 \%$, and the compensation effect is obvious. At the same time, the dynamic compensation performance of the system was studied. The rectifier was connected with a $40 \Omega$ resistance load; then a $40 \Omega$ load resistance is connected in parallel, and finally removed. It can be seen from Figure 19a that $U_{a 1}$ and $U_{a 2}$ are stable at a reference value, and the system has a good dynamic compensation performance if the power grid and load are all balanced, and it also shows the unit output of the novel power topology, which is seven levels. 


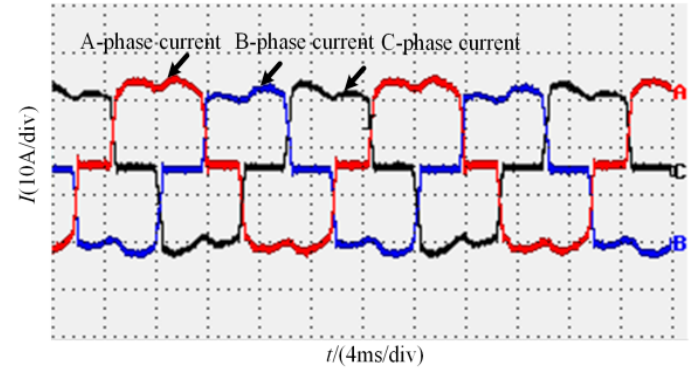

(a)

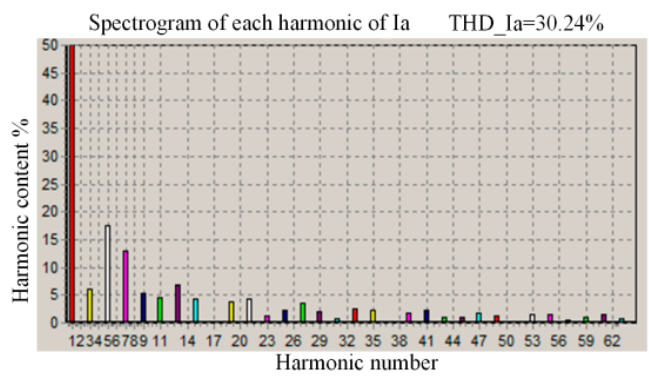

(b)

Figure 18. Before compensation: (a) Grid current; (b) Current THD.

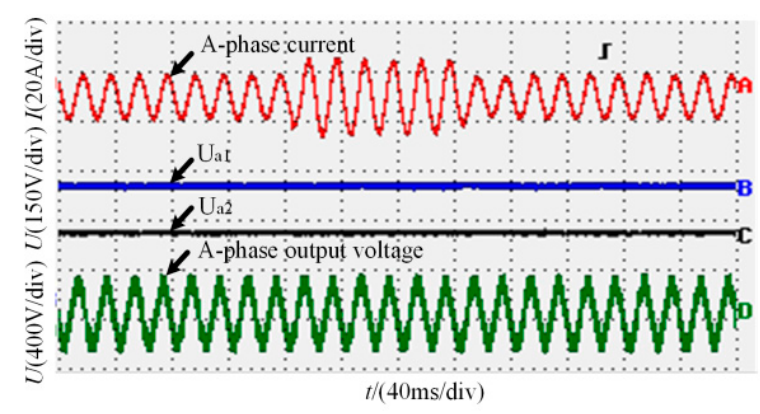

(a)

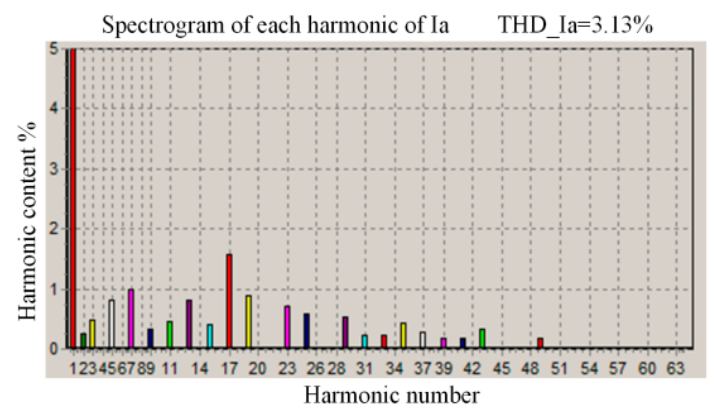

(b)

Figure 19. After compensation: (a) Grid current, two capacitor voltages, and the output voltage of the A-phase; (b) Current THD.

\section{Conclusions}

This paper proposes a novel seven-level power topology. Compared to the novel seven-level topology, each power switch in a traditional two-level topology withstands the total DC bus voltage, while some power switches in the novel seven-level topology only withstand one-third of the total DC bus voltage; therefore, the novel seven-level topology has large power capacity, and reduces the withstand voltage of the power switches. The novel seven-level topology makes the output waveform closer to a sine wave by increasing the number of output levels and thereby improves the quality of the output waveform. According to the simulation and experimental results in this paper, the compensated grid current THD with the seven-level APF is only 1\%-3\%, much lower than the traditional two-level and three-level APF whose compensated grid current THD is usually greater than $5 \%$, and the harmonic suppression effect is obvious. Compared to other seven-level topologies, the novel seven-level topology reduces the number of power switches and capacitors; thus reducing the size and cost of the device. Through the in-depth analysis of the working mechanism of the proposed topology, the engineering realization of the seven-level output is given. Besides, for the problem of capacitor-voltage imbalance in the application, an equalization control strategy with overall control and independent control of the two-stage capacitor voltage is proposed. In addition, the passive elements have been selected based on detailed mathematical analysis. Finally, from the above simulation and experimental work, we can see that the voltage control strategy described in this paper can achieve better cell capacitor-voltage regulation and the three-phase APF can achieve better compensation effect.

Author Contributions: H.G. conceived and designed the simulations and experiments; P.Z. analyzed the data; X.L. and S.F. wrote the paper; J.M. and R.L. checked the paper.

Funding: This research work was funded by the National Natural Science Foundation of China grant number 51177031 and the Science and Technology Planning Project of Guangdong Province of China(2016B010135001).

Conflicts of Interest: The authors declare no conflict of interest. 


\section{References}

1. Gadgune, S.Y.; Jadhav, P.T.; Chaudhary, L.R.; Waware, M.M. Implementation of shunt APF based on Diode Clamped and Cascaded H-bridge multilevel inverter. In Proceedings of the International Conference on Electrical, Computer and Communication Technologies (ICECCT), Coimbatore, India, 5-7 March 2015; pp. 1-7.

2. Choi, W.; Lam, C.; Wong, M.; Han, Y. Analysis of DC link voltage controls in three-phase four-wire hybrid active power filters. IEEE Trans. Power Electron. 2013, 28, 2180-2191. [CrossRef]

3. Hou, S.; Fei, J. Adaptive fuzzy sliding control with fuzzy sliding term for three-phase active power filter. In Proceedings of the IEEE International Conference on Control and Automation (ICCA), Hangzhou, China, 12-14 June 2013; pp. 1318-1323.

4. Lam, C.; Wong, M.; Choi, W.; Cui, X.; Mei, H.; Liu, J. Design and performance of an adaptive low-DC-voltage-controlled LC-hybrid active power filter With a neutral inductor in three-phase four-wire power systems. IEEE Trans. Ind. Electron. 2014, 61, 2635-2647. [CrossRef]

5. Alishah, R.S.; Hosseini, S.H.; Babaei, E.; Sabahi, M. Optimal Design of New Cascaded Switch-Ladder Multilevel Inverter Structure. IEEE Trans. Ind. Electron. 2017, 64, 2072-2080. [CrossRef]

6. Zhu, H.; Shu, Z.; Gao, F. Five-level diode-clamped active power filter using voltage space vector-based indirect current and predictive harmonic control. IET Power Electron. 2014, 7, 713-723. [CrossRef]

7. Banaei, M.R.; Jannati Oskuee, M.R.; Khounjahan, H. Reconfiguration of semi-cascaded multilevel inverter to improve systems performance parameters. IET Power Electron. 2014, 7, 1106-1112. [CrossRef]

8. Babaei, E.; Laali, S.; Bayat, Z. A Single-Phase Cascaded Multilevel Inverter Based on a New Basic Unit With Reduced Number of Power Switches. IEEE Trans. Ind. Electron. 2015, 62, 922-929. [CrossRef]

9. Chen, Z.; Wang, Z.; Li, M. A hybird cascade H-bridge seven-level converter for active power filter. In Proceedings of the IECON 2014-40th Annual Conference of the IEEE Industrial Electronics Society, Dallas, TX, USA, 29 October-1 November 2014; pp. 1041-1047.

10. Boora, K.; Kumar, J.; Himanshu. A new general topology for asymmetrical multilevel inverter with reduced number of switching components. In Proceedings of the 2017 Recent Developments in Control, Automation \& Power Engineering (RDCAPE), Noida, India, 26-27 October 2017; pp. 66-71.

11. Hameed, U.; Ali, M.; Sadiq, H.; Khawaja, A.H.; Abdullah Khalid, H. Comparative study of Cascaded H-Bridge Multi-level Inverter using different Phase Shifted PWM Techniques. In Proceedings of the 2018 International Conference on Power Generation Systems and Renewable Energy Technologies (PGSRET), Islamabad, Pakistan, 10-12 September 2018; pp. 1-6.

12. Singhai, S.; Pandey, A.; Singh, V. New Topology of Asymmtrical Multilevel inverter [15/29 Level]. In Proceedings of the 2018 International Conference on Current Trends towards Converging Technologies (ICCTCT), Coimbatore, India, 1-3 March 2018; pp. 1-6.

13. Koshti, A.K.; Rao, M.N. A brief review on multilevel inverter topologies. In Proceedings of the 2017 International Conference on Data Management, Analytics and Innovation (ICDMAI), Pune, India, 24-26 February 2017; pp. 187-193.

14. Sajedi, S.; Basu, M.; Farrell, M. New grid-tied cascaded multilevel inverter topology with reduced number of switches. In Proceedings of the 2017 52nd International Universities Power Engineering Conference (UPEC), Heraklion, Greece, 28-31 August 2017; pp. 1-6.

15. Amamra, S.; Meghriche, K.; Cherifi, A.; Francois, B. Multilevel Inverter Topology for Renewable Energy Grid Integration. IEEE Trans. Ind. Electron. 2017, 64, 8855-8866. [CrossRef]

16. Haji-Esmaeili, M.M.; Naseri, M.; Khoun-Jahan, H.; Abapour, M. Fault-tolerant structure for cascaded H-bridge multilevel inverter and reliability evaluation. IET Power Electron. 2017, 10, 59-70. [CrossRef]

17. Mora, A.; Juliet, J.; Santander, A.; Lezana, P. Dead-Time and Semiconductor Voltage Drop Compensation for Cascaded H-Bridge Converters. IEEE Trans. Ind. Electron. 2016, 63, 7833-7842. [CrossRef]

18. Dhanamjayulu, C.; Meikandasivam, S. Performance verific-ation of symmetric hybridized cascaded multilevel inverter with reduced number of switches. In Proceedings of the 2017 Innovations in Power and Advanced Computing Technologies (i-PACT), Vellore, India, 21-22 April 2017; pp. 1-5.

19. Hasan, M.M.; Abu-Siada, A. A novel three phase cascaded multilevel inverter topology. In Proceedings of the 2016 IEEE Industrial Electronics and Applications Conference (IEACon), Kota Kinabalu, Malaysia, 20-22 November 2016; pp. 31-35. 
20. Kangarlu, M.F.; Babaei, E. A Generalized Cascaded Multilevel Inverter Using Series Connection of Submultilevel Inverters. IEEE Trans. Power Electron. 2018, 28, 625-636. [CrossRef]

21. Srinivas, C.; PhaniSanthoshi, K.; AppaRao, G.V.; Siva, K.N.V. A Novel Seven Level Asymmetrical Inverter Topology to Reduce Total Harmonic Distortion. In Proceedings of the 2018 International Conference on Current Trends towards Converging Technologies (ICCTCT), Coimbatore, India, 1-3 March 2018; pp. 1-4.

22. Ramya, D.; Mary Antony, A.S. A reconfigurable five/seven level inverter with reduced switching losses. In Proceedings of the 2017 International Conference on Computation of Power, Energy Information and Commuincation (ICCPEIC), Melmaruvathur, India, 22-23 March 2017; pp. 656-659.

23. Yarlagadda, A.K.; Eate, V.k.; Babu, Y.S.K.; Chakraborti, A. A Modified Seven Level Cascaded H Bridge Inverter. In Proceedings of the 2018 5th IEEE Uttar Pradesh Section International Conference on Electrical, Electronics and Computer Engineering (UPCON), Gorakhpur, India, 2-4 November 2018; pp. 1-6.

24. Guo, H.F.; Chen, M.; Cao, Y.; Ma, Q.D.; Ling, Z.B. Design of 2MW/10kV cascaded H-bridge power conversion system. In Proceedings of the 2014 International Conference on Power System Technology, Chengdu, China, 20-22 October 2014; pp. 3335-3340.

25. Kawakami, N.; Ota, S.; Kon, H.; Konno, S.; Akagi, H.; Kobayashi, H.; Okada, N. Development of a 500-kW Modular Multilevel Cascade Converter for Battery Energy Storage Systems. IEEE Trans. Ind. Appl. 2014, 50, 3902-3910. [CrossRef]

26. Townsend, C.D.; Summers, T.J.; Betzl, R.E. Impact of Practical Issues on the Harmonic Performance of Phase-Shifted Modulation Strategies for a Cascaded H-Bridge StatCom. IEEE Trans. Ind. Electron. 2014, 61, 2655-2664. [CrossRef]

27. Angulo, M.; Lezana, P.; Kouro, S.; Rodriguez, J.; Wu, B. Level-shifted PWM for Cascaded Multilevel Inverters with Even Power Distribution. In Proceedings of the 2007 IEEE Power Electronics Specialists Conference, Orlando, FL, USA, 17-21 June 2007; pp. 2373-2378.

28. Sochor, P.; Akagi, H. Theoretical and Experimental Compa-rison Between Phase-Shifted PWM and Level-Shifted PWM in a Modular Multilevel SDBC Inverter for Utility-Scale Photovoltaic Applications. IEEE Trans. Ind. Appl. 2017, 53, 4695-4707. [CrossRef]

29. Alex Bao Zambra, D. Comparison of Phase-Shift and Step Wave Modulation Technique applied to Symmetrical Cascaded Multilevel Inverter. IEEE Lat. Am. Trans. 2013, 11, 1156-1162. [CrossRef]

30. Ko, Y.; Andresen, M.; Buticchi, G.; Liserre, M. Power Routing for Cascaded H-Bridge Converters. IEEE Trans. Power Electron. 2017, 32, 9435-9446. [CrossRef] 